\title{
CORRIGENDUM
}

\section{Psychosocial correlates of apparent treatment-resistant hypertension in the Jackson Heart Study}

\author{
AJ Shallcross, M Butler, RM Tanner, AP Bress, P Muntner, D Shimbo, G Ogedegbe, M Sims and TM Spruill
}

Journal of Human Hypertension (2017) 31, 486; doi:10.1038/jhh.2017.19

Correction to: Journal of Human Hypertension (2017) 31, 474-478; doi:10.1038/jhh.2016.100; published online 26 January 2017

Since the online publication of this article, it has been noted that the author name A Bress was incorrect and should be replaced with AP Bress.
This error has now been rectified and the corrected article appears in this issue. The html and online pdf versions have also been rectified, and now carry the corrected paper.

The authors would like to apologise for this error. 